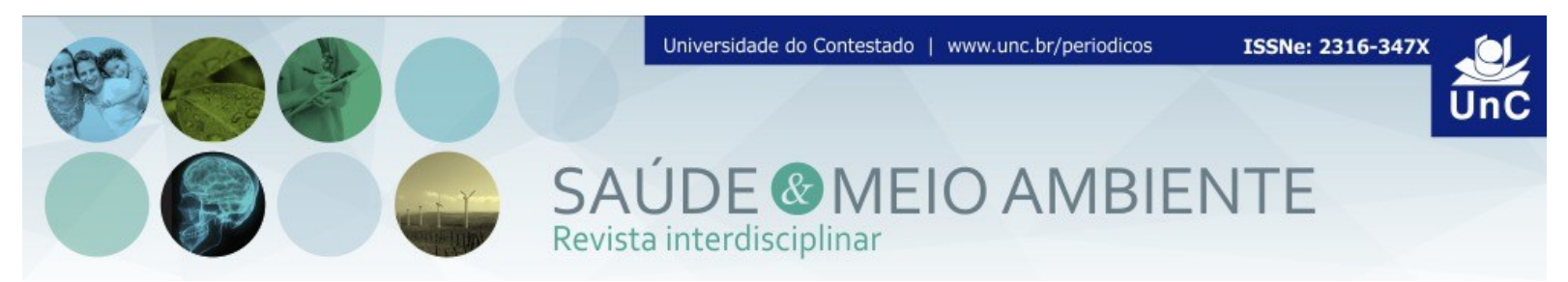

\title{
OURO PRETO E A GESTÃO DO PATRIMÔNIO AMBIENTAL TURÍSTICO POLITICA E PLANEJAMENTO, ESTUDO DE CASO
}

\author{
Simone Fernandes Machado ${ }^{1}$ \\ Ricardo Eustáqui Fonseca Filho ${ }^{2}$
}

\begin{abstract}
RESUMO: O presente trabalho visou, com base em pesquisas de dados primários e secundários, ordenados mediante indicadores de qualidade ambiental adotados pelo Estado de Minas Gerais, analisar a qualidade ambiental dos atrativos turísticos naturais de Ouro Preto (MG), a fim de avaliar a eficiência da gestão pública municipal. Para obtenção de dados, foi realizada pesquisa bibliográfica, levantamentos em campo e documentais em 2014. As legislações ambientais vigentes no Brasil possui, entre os seus objetivos, a função de assegurar boas condições ambientais e a participação popular. Para elaboração de diagnóstico ambiental, o Estado de Minas Gerais adotou seis índices de qualidade. Porém, será que, na pratica, tais índices são viáveis e de fácil acesso? Os processos existentes são eficientes e satisfatórios? Como eles podem auxiliar no planejamento da atividade turística? Nesse contexto, tomando como referência a lei que estabelece a Política Nacional de Meio Ambiente e a que estabelece o Sistema Nacional de Unidades de Conservação da Natureza, Como resultado, constatou-se que os dados para o cálculo dos índices, essenciais para a obtenção dos indicadores são de difícil acesso, devido à ausência de estudos técnicos e compilação de dados governamentais de forma eficiente, sugerindo-se a melhoria na aplicação dos princípios da administração pública "eficiência" e "publicidade".
\end{abstract}

Palavras-Chave: Planejamento Turístico. Gestão Ambiental. Índice de Qualidade Ambiental.

\section{BLACK AND GOLD MANAGEMENT OF EQUITY ENVIRONMENTAL TOURISM POLICY AND PLANNING, CASE STUDY}

ABSTRACT: This study aimed, based on research of primary and secondary data, ordered by environmental quality indicators adopted by the State of Minas Gerais, analyze the environmental quality of natural tourist attractions of Ouro Preto (MG), in order to further evaluate the efficiency the municipal public administration. To obtain data, literature search was conducted field surveys and documentary in 2014. The current environmental legislation in Brazil has, among its objectives, the role of ensuring environmentally sound and popular participation. For the preparation of environmental assessment, the state of Minas Gerais adopted six quality levels.

\footnotetext{
${ }^{1}$ Bacharel em Turismo pela Universidade Federal de Ouro Preto, Agente Administrativo na Prefeitura Municipal de Ouro Preto. Minas Gerais. Brasil. E-mail: sissamachadofernan@hotmail.com

${ }^{2}$ Mestre e Doutorando em Ciências Naturais, pelo Departamento de Geologia - Escola de Minas UFOP é Professor Assistente do Curso de Bacharelado em Turismo - UFOP. Minas Gerais. Brasil. E-mail: simonexveiga1@yahoo.com.br
} 
However, it shall be, in practice, these indices are viable and easily accessible? Existing processes are efficient and satisfactory? How they can assist in the planning of tourism? In this context, with reference to the law establishing the National Environment and establishing the National System of Protected Areas of Nature Policy, As a result, it was found that the data for the calculation of indices, essential for obtaining the indicators are difficult to access due to lack of technical studies and compile government data efficiently, suggesting the improvement in the application of the principles of public administration "efficiency" and "advertising".

Keywords: Tourism Planning. Environmental Management. Environmental Quality Index.

\section{INTRODUÇÃO}

À medida que as cidades expandem-se, a vida de seus residentes torna-se cada vez mais difícil em decorrência da presença constante e gradativa, de diversos agentes poluentes que debilitam o organismo humano, ou desencadeiam patologias vinculadas ao estresse, como é o caso da poluição sonora e visual que podem afetar o sistema nervoso e cardiovascular.

Nesse contexto, amplia-se a busca por atrativos naturais, muitos destes localizados em áreas de preservação ambiental, desencadeando na atividade de locomoção e turismo. No entanto, as atividades humanas podem representar uma pressão negativa sobre o meio ambiente, podendo afetar o seu estado, onde o setor público deve investir em ações para prevenir ou mitigar os impactos negativos ocasionados.

Porém, que mecanismos podem ser utilizados pela administração pública para diagnosticar a qualidade ambiental? Como ocorre a participação popular? A utilização dos indicadores ambientais estabelecidos pelo Estado podem auxiliar no planejamento e ordenamento da atividade turística? De que maneira? As informações necessárias para obtenção dos indicadores são acessíveis à população? E por fim, os processos de participação publica existentes são eficientes e satisfatórios?

Com essa preocupação, tomando como referência a Lei $n^{\circ}$. 6.938/81, da Política Nacional de Meio Ambiente, a Lei $n^{\circ}$. 9.985, de 18 de julho de 2000, que dispõe sobre o Sistema Nacional de Unidades de Conservação da Natureza SNUC, o presente trabalho visa avaliar as condições ambientais, a participação popular, e a eficiência da gestão pública no município de Ouro Preto, Minas Gerais, em especial, no que tange a preservação ambiental das Unidades de Conservação Municipais e o desenvolvimento das atividades turísticas. 


\section{METODOLOGIA}

Para obtenção dos dados necessários foram realizadas entrevistas à órgãos ambientais (Instituto Estadual de Florestas, Secretaria Municipal de Meio Ambiente e Cadastro Nacional de Unidades de Conservação) e 11 visitas in loco nos referidos parques entre os meses de março a maio de 2014; levantados documentos existentes nas Secretarias Municipais de Ouro Preto (Meio Ambiente e Saúde) e demais autarquias competentes; busca por informação em sites institucionais. Posteriormente dados foram compilados, agrupados em indicadores e analisados frente o embasamento teórico da legislação de proteção ao patrimônio ambiental vigente. Optou-se, no trabalho pela escolha de indicadores que de alguma maneira influenciam nos elementos fundamentais da natureza: ar, água, solo e cobertura vegetal. Estes indicadores foram agregados e transformados no Índice de Qualidade do Meio Ambiente - IQMA para o município de Ouro Preto.

Ao final, foi realizada uma análise comparativa dos indicadores ambientais obtidos para a Ouro Preto como um todo para as Unidades de Conservação no município, de acordo com os valores estabelecidos na legislação ambiental vigente no estado de Minas Gerais. Posteriormente, comparou-se os dados obtidos por meio dos indicadores às possíveis aplicações práticas para o planejamento e a gestão dos atrativos turísticos naturais localizados em Unidades de Conservação abertas à visitação pública a fim de avaliar sua aplicabilidade e eficiência. Como resultado final, foram listadas tendências favoráveis e desfavoráveis à sustentabilidade do município, com base nos resultados obtidos pelo cálculo dos referidos indicadores, em comparação à níveis estaduais.

Como resultado constatou-se que a análise dos indicadores como forma de monitoramento de políticas públicas e ferramenta para o planejamento e gestão de atrativos turísticos demonstrou-se insuficiente, devido à dificuldade de obtenção destes e as peculiaridades de cada Unidade de Conservação, embora satisfatória no que tange a análise do contexto geral do município, abrangendo diversas dimensões da sustentabilidade.

\section{CONTEXTUALIZAÇÃO E REVISÃO BIBLIOGRÁFICA}

Antes de 1960, o termo ambiente tinha pouco ou nenhum sentido político e social. Os primeiros tempos do ambientalismo moderno foram dominados por confrontações entre os chamados ambientalistas e desenvolvimentistas. Os ambientalistas acreditavam que o mundo seria destruído se as pessoas não mudassem sua visão de meio ambiente. Já os desenvolvimentistas acreditavam que o progresso e o bem estar, social e econômico, eram necessários caso a civilização quisesse prosperar. 
A partir da década de 1970 a preocupação com o meio ambiente ecoou na sociedade, com a visão que o problema não poderia ser de responsabilidade local, mas sim global. Posteriormente, grandes eventos de repercussão mundial passaram a motivar pessoas acerca da temática. A Conferência Mundial de Estocolmo, em 1972; O Seminário Internacional de Educação em Belgrado em 1975; a United Nations Conference on Enviromentand Development (UNCED); ou ECO-92, realizada no Rio de Janeiro em 1992 podem ser citados como exemplos (FERREIRA, 2007). O evento ECO-92 ocasionou na produção de um documento conhecido como Agenda 21, que se tornou referência no que concerne a implantação de programas e políticas de governos e empresas em âmbito mundial. Ainda nos eventos supramencionados, surgiram diversos termos, expressões e definições aos quais foram atribuídos conceitos, muitas vezes divergentes, alvo de discussão e polêmica, vieram à tona, tais como: meio ambiente, poluição, degradação, impacto ambiental e desenvolvimento sustentável.

No que compele a gestão ambiental, o termo sustentabilidade é amplamente utilizado. E, embora existam diversas definições para explicá-lo, eles mantêm a mesma interpretação como: "Desenvolvimento sustentável implica usar os recursos renováveis naturais de maneira a não degrada-los ou elimina-los, ou diminuir sua utilidade para as gerações futuras" (BARONI, 1992, p. 16). Pode-se, portanto, observar que $\mathrm{o}$ crescimento sustentável difere da abordagem tradicional de crescimento econômico, orientado para a produção. Ao crescimento sustentável cabe incorporar indicadores qualitativos, voltados para o bem estar da população.

Com relação às expressões, meio ambiente é a mais complexa e controversa relacionada à temática, pois, a mesma refere-se a uma realidade abrangente, nem sempre restrita ao ambiente natural podendo incorporar também ambientes artificiais - ou construídos pelo homem; ambientes culturais - tangíveis e intangíveis dentre outros. Embora a expressão "meio ambiente" encontrar-se consagrada, ainda é alvo de críticas, pois, conforme Sirvinskas (2002), a palavra meio refere-se àquilo que está no meio de alguma coisa, enquanto ambiente trata do lugar em que os seres vivos habitam. No entanto, salienta-se que a palavra refere-se a um conceito, não podendo, portanto, ser analisada de forma isolada.

Muitas são as doenças decorrentes de um ambiente poluído e/ou desequilibrado, Freire (2013) coloca que, a presença de microrganismos e substâncias tóxicas favorece a proliferação de doenças, podendo ser nocivos à saúde humana, responsáveis ainda por epidemias e endemias. Ao conjunto de medidas que visa prever ou modificar condições do ambiente com a finalidade de prevenir doenças e promover a saúde dá-se o nome de saneamento. Um dos grandes problemas enfrentados pela gestão pública e privada, e pelos profissionais responsáveis pela mesma, é a ausência de informações necessárias para a tomada de decisões. As suposições infundadas atrapalham no estabelecimento da viabilidade dos empreendimentos e oferecem poucos subsídios técnicos para a atuação dos governantes. Para a implantação de um projeto, seja ele qual for, devese comparar a estimativa de seus benefícios decorrentes com os custos incorridos por meio do valor obtido pela divisão dos benefícios pelos custos. 
O desenvolvimento tecnológico e a globalização trouxeram benefícios para a humanidade, em especial aos habitantes de países desenvolvidos, contudo, bens indispensáveis à vida tais como a água, a terra e o ar foram transformados em mercadoria. Desigualdade social, desemprego, marginalidade, falta de saneamento básico e urbanização sem planejamento adequado são alguns dos problemas decorrentes de tais processos. Logo, cabe à gestão, o estabelecimento de programas como os de planejamento, avaliação e gerenciamento de riscos.

Mediante as constatações anteriores, surgiu a necessidade do desenvolvimento de parâmetros para mensurar a qualidade ambiental frente ao desenvolvimento. Braga e Freitas (2002) apontam o surgimento de propostas de construção de indicadores ambientais e de sustentabilidade no final da década de 1980 que visavam subsidiar a formulação de políticas nacionais e acordos internacionais, bem como a tomada de decisão de acordos públicos e privados, fornecendo maior funcionalidade e concretude ao conceito de sustentabilidade. Para que isso ocorra, foram desenvolvidos então os indicadores. O estudo de Silva (2002) demonstrou que a expansão acelerada da área urbana, nos últimos anos, acarretou ainda em inúmeros problemas ambientais, advindos da falta de consciência, tanto da população local como dos órgãos administrativos.

As legislações ambientais vigentes no Brasil possuem a função de garantir boas condições ambientais e assegurar a participação popular em todo o seu processo de elaboração, implantação e monitoramento. Objetivando assim, promover a disseminação de práticas que assegurem 0 desenvolvimento sustentável, a conscientização ambiental e a mudança de postura na sociedade como um todo e o sucesso nas estratégias de conservação ambiental, mas, muitas vezes, as mesmas não são implementadas e fiscalizadas com eficácia, não atingindo seu objetivo inicial de preservação.

Para assegurar a efetivação do proposto nas mesmas pelo poder público, foram desenvolvidos indicadores qualitativos, baseados em índices quantitativos, que visam mensurar a situação ambiental e nortear o planejamento estratégico das medidas preventivas e/ou mitigadoras, de proteção ao meio ambiente como um todo. Tais índices visam ainda facilitar a análise da situação atual, com intuito de garantir maior eficiência no processo de implantação, na coordenação das condições e dos processos de proteção ambiental de uma determinada localidade, empreendimento ou procedimento, norteia ainda as ações dos responsáveis pela sua gestão. O Estudo de Impacto Ambiental - EIA, e o Relatório de Impacto Ambiental - RIMA, asseguram os estudos prévios dos impactos que poderão vir a ocorrer, com a instalação e/ou operação de um determinado empreendimento conforme coloca Lisboa (2008).

Indicador é proveniente do latim indicare, cujo significado é destacar mostrar, anunciar, tornar público, estimar. Logo, os indicadores transmitem informações e esclarecem fenômenos não imediatamente observáveis (MERICO, 1996 apud RUFINO, 2002). Os indicadores compõem um método pelo qual a avaliação pública avalia o seu desempenho com relação ao estabelecimento de políticas e programas voltados para a preservação do meio ambiente. A função dos indicadores é, portanto, resumir grande quantidade de dados, mensurá-los, tornando acessível o 
seu entendimento. Sendo aos índices, atribuídas às funções de transformar os dados e suas variáveis em valores numéricos. A sustentabilidade é determinada por um conjunto de fatores que devem ser contemplados e que são analisados por meio dos indicadores, obtidos por meio dos índices.

Os indicadores devem possuir: características representativas e científicas; ser quantificáveis, de fácil interpretação e divulgação; apresentar tendências ao longo do tempo e indicar com antecedência o surgimento das irreversíveis; ser sensíveis a mudanças no ambiente ou na economia; ser referente a dados já existentes ou coletados a custos razoáveis e possibilitar atualizações a intervalos regulares de tempo; ser baseados em dados confiáveis e possuir um parâmetro com que possam ser comparados (GILBERT; FEENSTRA, 1999 apud CORRÊA et. al., 2010). Em Minas Gerais, os indicadores foram agregados em seis temas: Ar, Água, Solo, Biodiversidade, Institucional e Socioeconomia (FEAM, 2011).

Ainda segundo Ramos (1997), os indicadores e os índices são projetados para simplificar a informação sobre fenômenos complexos de modo a melhorar a comunicação. Podem ser aplicados em uma série de situações problemas como: atribuição de recursos; classificação de locais; cumprimento de normas legais; análise de tendências; informação ao público; investigação científica. Os indicadores são usados pela gestão como instrumentos que permitem a avaliação de uma situação e sua possível evolução. O autor Dahl (1997) afirma que o maior desafio dos indicadores é fornecer um retrato da situação de sustentabilidade, de uma maneira simples, apesar da incerteza e da complexidade.

Até os anos 1960, poluir era permitido. Alguns avanços importantes no que tange a proteção ambiental foram dados nas décadas seguintes, como a edição do Código Florestal. Visando mitigar posturas poluentes o Brasil substituiu a antiga legislação setorizada e instituiu a Política Nacional do Meio Ambiente, Lei nº.1.981, lei está, ainda vigente.

Para fins legais, conforme Art. 225 da Constituição Federal, entende-se por meio Ambiente como sendo: "o conjunto de condições, leis, influências e interações de ordem física, química e biológica que permite, abriga e rege a vida em todas as suas formas; bem ambiental o que pertence ao senso comum" (BRASIL, 1988). O desenvolvimento sustentável busca harmonia entre o desenvolvimento econômico e a utilização dos recursos naturais de forma consciente, equilibrada ou sustentável.

A Política Nacional do Meio Ambiente estabelecida em 1981 mediante a edição da Lei $n^{\circ}$. 6.938, criou o Sistema Nacional do Meio Ambiente - SISNAMA, que congrega órgãos e instituições ambientais da União, dos Estados, dos Municípios e do Distrito Federal com a finalidade de cumprir os princípios constitucionais. A Constituição Federal (BRASIL, 1988) estabelece que, desde que em conformidade com a Legislação Federal e Estadual, os municípios podem editar normas a fim de atender à realidade local.

As Unidades de Conservação (UC) integram o SNUC são entendidas como 
Espaço territorial e seus recursos ambientais, incluindo as águas jurisdicionais, com características naturais relevantes, legalmente instituídas pelo Poder Público, com objetivos de conservação e limites definidos, sob regime especial de administração, ao qual se aplicam garantias adequadas de proteção. (BRASIL, 2000).

Ainda de acordo com a lei supracitada, as UCs dividem-se em dois grupos: Unidades de Proteção Integral e Unidades de Uso Sustentável. O Art. 22 (idem) esclarece que as unidades de conservação são criadas por ato do Poder Público. Nada impede, contudo, que se utilize à lei, como instrumento para sua criação. As Unidades de Proteção Integral são compostas por cinco categorias de unidades de conservação, a saber: Estação Ecológica; Reserva Biológica; Parque Nacional; Monumento Natural; Refúgio de Vida Silvestre. Já as Unidades de Uso Sustentável são compostas por sete categorias de unidades de conservação: Área de Proteção Ambiental; Área de Relevante Interesse Ecológico; Floresta Nacional; Reserva Extrativista; Reserva de Fauna; Reserva de Desenvolvimento Sustentável; Reserva Particular do Patrimônio Natural.

O Município de Ouro Preto possui 11 Unidades de Conservação cadastradas, sendo seis de âmbito estadual e cinco municipais, oito dessas constam nos arquivos do Cadastro Nacional de Unidades de Conservação - CNUC, as demais, estão em processo de inclusão CNUC (2014), sendo ainda 10 delas cadastradas em categorias que permitem a visitação pública, compatíveis com a prática do turismo.

O turismo é um relevante setor da atividade econômica no Brasil, sendo tomado como uma alternativa na geração de renda e emprego, já que, quando bem planejado e gerido, oferece menor impacto ao meio ambiente, comparado às outras atividades dinâmicas da economia tais como a mineração e a agricultura. Porém, Swarbrooke (2000) corrobora que, quando se visa a sustentabilidade da atividade, o turismo não deve estar embasado apenas na proteção da natureza, mas também à viabilidade econômica a longo prazo e a justiça social.

A atividade do turismo acontece durante o deslocamento e a permanência do indivíduo fora da sua residência. Os negócios turísticos são os realizados nos equipamentos ou durante a prestação de serviços que os turistas utilizam na preparação e na execução da sua atividade (BARRETTO, 2003). Sendo, portanto, um ato praticado por pessoas que realizam uma atividade específica de lazer, fora das suas respectivas cidades e que utilizam, para atingir objetivos tais como equipamentos e serviços cuja prestação constitui um negócio. No que tange as Unidades de Conservação, a visitação pode trazer como benefícios o auxílio financeiro para a manutenção das áreas e outros financiamentos que auxiliem na conservação destas áreas.

De acordo com SEMAD-MG (2009), a Avaliação Ambiental Estratégica - AAE - é um processo de identificação de impactos ambientais e de alternativas que os minimizam na implantação de políticas e projetos governamentais. Geralmente, a avaliação é utilizada na elaboração das propostas dessas ações estratégicas, sistematizando os resultados e sua utilização para tomadas de decisões ambientalmente sustentáveis devendo ser elaborada de forma pública e participativa. 
O EIA/RIMA é o mecanismo que estabelece a realização de diagnóstico das condições ambientais encontradas, os possíveis impactos decorrentes da instalação de um dado empreendimento, assim como a previsão de medidas mitigadoras para os possíveis impactos decorrentes do mesmo. Na ausência de um mecanismo compatível que norteie as ações da gestão pública, no que tange a proteção de seus recursos naturais, os indicadores ambientais são usados como instrumentos que permitem a avaliação de um espaço geográfico e as condições que o envolvem de uma forma global, e sua possível evolução através do tempo.

Com intuito de avaliar se as condições ambientais, os processos utilizados pela gestão e a participação popular estão em conformidade legal com a Lei $n^{\circ}$. 6.938/81 que estabelece a Política Nacional de Meio Ambiente a da Lei $n^{\circ}$. 9.985, de 18 de julho de 2.000, que dispõe sobre o Sistema Nacional de Unidades de Conservação da Natureza - SNUC, o presente trabalho visa avaliar as condições ambientais da cidade de Ouro Preto, baseado em indicadores pré-estabelecidos pela Fundação Estadual Ambiental - FEAM, tendo como foco ainda o planejamento e a gestão da atividade turística nas unidades de conservação situadas no município.

\section{RESULTADO E DISCUSSÃO}

A cidade de Ouro Preto, localizado no Estado de Minas Gerais, próximo ao centro urbano de Belo Horizonte, destaca-se no cenário turístico nacional devido à presença de monumentos arquitetônicos, históricos, de grande beleza e interesse cultural. No entanto, a cidade conta ainda com inúmeros monumentos naturais de considerável relevância principalmente por suas características geomorfológicas, pedológicas, biogeográficas, hidrográficas e climáticas passíveis de aproveitamento para a atividade turística e que carecem de um planejamento adequado.

Neste contexto, serão analisados a aplicação dos índices de qualidade para avaliar a qualidade e integridade destes para a implementação da atividade turística. Visando uma melhor apresentação dos dados, os mesmos serão apresentados em duas etapas, a primeira tratará o município de Ouro Preto de uma forma geral e a segunda parte focará nas Unidades de Conservação.

\section{OS INDICADORES AMBIENTAIS APLICADOS À CIDADE DE OURO PRETO}

O Indicador Institucional é avaliado de acordo com a porcentagem de recursos públicos para meio ambiente em relação ao total executado. A Lei $n^{\circ}$. 747 de 28 de dezembro de 2011 se refere ao orçamento fiscal do município de Ouro Preto para o exercício financeiro de 2012 e estima a receita em $\mathrm{R} \$ 255.000 .000,00$ (duzentos e cinquenta e cinco milhões de reais) e fixa a despesa em igual 
importância. Cabe ressaltar que essa mesma lei fixa as despesas de saneamento em $R$ \$ 32.124.099,91; de gestão ambiental em $R$ \$ 2.826.663,60; de educação em $\mathrm{R} \$$ 46.944.527,74 e de urbanismo em $\mathrm{R} \$$ 8.103.000,00 PMSB (2013). Ou seja, cerca de $35,29 \%$ da receita municipal, maior que a média do Estado de Minas Gerais. Logo, este índice aponta para existência de orçamento e meios institucionais satisfatórios que visam assegurar a qualidade ambiental, entretanto, na prática, observa-se que tais recursos são mal distribuídos e/ou geridos, tornando muitas das ações de proteção ineficazes. Ressalta-se ainda que os dados são apresentados de forma complexa pela administração, dificultando a compreensão e o acesso à informação pela população.

O Indicador Ar é calculado, anualmente, pela porcentagem do número de amostras em atendimento ao padrão de $50 \mu \mathrm{g} / \mathrm{m}^{3}$ de ar, em relação ao número total de amostras para o parâmetro PM 10 (FEAM, 2011). A metodologia adotada para o Estado considera a qualidade do ar boa quando as concentrações médias, durante um período de 24 horas, não ultrapassam o padrão estabelecido para a média anual, que é de $50 \mu \mathrm{g} / \mathrm{m}^{3}$ de ar. A FEAM disponibiliza relatórios do monitoramento do ar em seu site institucional, porém, tal monitoramento só ocorre na região metropolitana de Belo Horizonte. Existem ainda estações de monitoramento em municípios industriais tais como Itabira, Paracatu e Ipatinga FEAM (2014), porém, Ouro Preto não conta com tal serviço de monitoramento inviabilizando a obtenção de tal indicador. Cabe lembrar que este monitoramento é de extrema importância para controle de doenças respiratórias e cardiovascular na população, em especial pela presença de indústrias na cidade. $O$ ordenamento da atividade turística também carece de tais dados, em especial no que concerne o planejamento e a gestão de transportes.

O Indicador Água está diretamente relacionado à Demanda Bioquímica de Oxigênio - DBO; Coliformes termotolerantes; Oxigênio dissolvido - OD; O índice de contaminação por toxidez; Porcentagem de população com esgotos tratados ou dispostos adequadamente (FEAM, 2011). No município de Ouro Preto, como um todo, o abastecimento de água se dá através de rede geral de distribuição da Superintendência Municipal de Água e Esgoto - SEMAE e atingem 89,2\% da população localizada na sede e além de aglomerados urbanos nos 12 distritos, segundo dados do IBGE (2010). Salienta-se que parcela significativa da população $(10,8 \%)$ utiliza outros meios tais como poço ou nascente na propriedade como forma de abastecimento IBGE (2010).

O sistema de tratamento de esgoto de Ouro Preto conta com apenas uma Estação de Tratamento de Esgoto - ETE, em operação no distrito de São Bartolomeu. Porém, há um projeto para a construção de uma outra ETE, localizada na sede do município, na região denominada "Antigo Osso de Boi" às margens da rodovia dos Inconfidentes, sentido Ouro Preto - Mariana, ao sul do perímetro urbano do município de acordo com o Plano Municipal de Saneamento Básico (OURO PRETO, 2013, p. 277).

Os dados apresentados no documento (OURO PRETO, 2013, p. 139) alertam que o Sistema de Esgotamento Sanitário de Ouro Preto não é satisfatório, visto que atualmente, o sistema possui rede coletora de efluentes domésticos apenas na 
região central e no bairro Itacolomi. Nas demais áreas do município, principalmente em áreas periféricas, os efluentes são lançados em galerias de águas pluviais, diretamente nos corpos hídricos, na drenagem natural ou são utilizados sistemas de tratamento individual em desconformidade com os padrões mínimos de construção, como a fossa negra e sumidouros, também presentes em algumas Unidades de Conservação Estaduais tal como na Floresta do Uaimií e no Parque Natural Municipal das Andorinhas. Logo, o indicador água aponta para carência de políticas de saneamento no município. A visitação turística na cidade tende a agravar esse quadro, uma vez que aumenta a geração de efluentes sanitários e a demanda por água, que costuma não ser suficiente para atender moradores e visitantes em período de alta temporada.

Quanto aos resíduos sólidos, Ouro Preto possui um aterro controlado. Porém, este aterro está em fase final de utilidade. A gestão municipal busca, ainda sem êxito, por novas alternativas, mais eficientes, para a destinação dos resíduos. Logo, este indicador também apontou para um quadro de deficiência administrativa. Há ainda problemas relacionados à dinâmica da coleta, agravada por fatores geográficos, tais como as ladeiras de pouco ou nenhum acesso, no município o que dificulta a descentralização da oferta turística para os centros periféricos.

O Indicador de Biodiversidade é obtido pela porcentagem de área desmatada em relação à área total; porcentagem de área com vegetação nativa em relação à área total.

Os desmatamentos no Estado de Minas Gerais são controlados pelo IEF, segundo autorizações emitidas, a partir da análise das demandas e de vistorias de campo, que são registradas em sistema próprio. A essas áreas são somadas as áreas de desmatamentos ilegais, registradas por autos de infração pelo IEF. O padrão de desempenho adotado é o de desmatamento zero.

De acordo com a Organização Não-Governamental Brigada Voluntária 1 Núcleo Ouro Preto (2013), a alta ocorrência de incêndios, principalmente no inverno. O município possui ainda histórico de incêndio criminosos, que são agravados pelo período de seca, que compreende os meses de maio à setembro, de acordo com a classificação de Köppen. Ouro Preto possui 24.359,2332 hectares (há) em Unidades de Conservação, ou seja, $19,56 \%$ da área total de Ouro Preto que, segundo IBGE (2014) possui o equivalente à $124.500,0000$ ha. Comparado ao padrão de desempenho adotado pelo estado, que representa $10 \%$ da área total da região avaliada, critério sugerido durante o Congresso Mundial de Parques em 1982, Ouro Preto possui um bom desempenho, estando a 9,56\% acima da média proposta como referência para este indicador.

Apesar dos dados serem satisfatórios, e preciso salientar que os mesmos encontram-se fragmentados. Não há uma padronização que facilite o acesso a tais informações uma vez que as unidades de conservação são cadastradas em instâncias diferentes. Sendo apenas 8, das 11 unidades existentes cadastradas em instância Federal, no CNUC (Figura 3). Existe ainda o percentual de áreas de preservação permanente - APP, as Reservas de Propriedade Particular - RPPNs, as unidades de conservação em fase de estudos para sua implementação tais como o 
Jardim Botânico Municipal e a Serra do Gandarela. Tais áreas estão definidas no Plano Diretor Municipal, Código de Posturas e na Lei Orgânica, porém, o mesmo encontra-se desatualizado, não oferecendo, portanto dados eficientes que subsidiem o cálculo de tais áreas, inviabilizando o cálculo preciso dos índices que compões este indicador, embora os dados existentes apontem para um panorama positivo para o município.

Quanto às UC municipais (Figura 1) ressalta-se que o valor apresentado anteriormente é o cálculo da soma das áreas, em hectares, das onze unidades inventariadas, excluídas as sobreposições e as áreas localizadas fora dos limites do município. Tal contexto também favorece o desenvolvimento do turismo em áreas naturais.

Figura 1 - Mapa UCs cadastradas no CNUC.

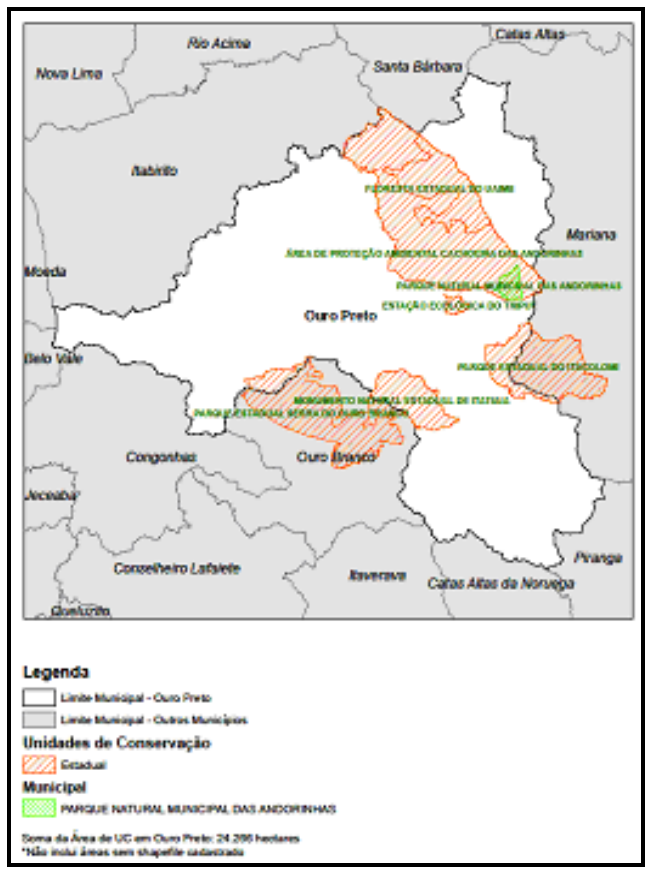

Fonte: Ministério Meio Ambiente (2014).

O Indicador Solo é calculado pela porcentagem de população com disposição adequada de lixo; Quilograma de agrotóxico/hectare de área cultivada (FEAM, 2011). De acordo com dados da Prefeitura Municipal, a população rural do município não é atendida pelo serviço de coleta convencional, nem coleta seletiva. Entretanto, $100 \%$ dos domicílios da área urbana da sede e dos distritos administrativos são atendidos por este serviço, ou seja, cerca de $90 \%$ da população é atendida pelo serviço de coleta convencional de resíduos sólidos urbanos, Plano Municipal de Saneamento Básico (2013, p. 307). Ressalta-se aqui que a meta a alcançar é $100 \%$ da população atendida pelo serviço de coleta de resíduos sólidos. Quanto ao percentual de quilograma de agrotóxicos por hectare de área cultivada, não foram encontrados dados precisos que subsidiem a obtenção de tal índice, no entanto, como a utilização de agrotóxico é proibida nas áreas contidas no interior das unidades de conservação, tendo em vista o alto percentual de áreas em hectares 
protegidas no município, estima-se que este índice apresente percentual considerado positivo e satisfatório e que esteja dentro dos limites aceitáveis.

O Indicador Socioeconomia é obtido por dados sobre a mortalidade infantil. De acordo com dados do PNDU Ouro Preto possui, alta taxa de mortalidade, com $30,52 \%$ mortes, até os cinco anos de idade, para cada 1.000 crianças nascidas vivas. Valor alto, comparado à média estadual de 12,4 mortes para cada 1.000 crianças nascidas vivas. Os dados divulgados pelo DATASUS apontam que, em 2008, o município de Ouro Preto apresentou 35,6\% da mortalidade proporcional para doenças do aparelho circulatório, 15,2\% para neoplasias (tumores), $11,9 \%$ de doenças do aparelho respiratório, sendo estas as principais causas de óbito infantil como demonstrado na figura 3.

Figura 2 - Principais doenças causadoras de mortes em Ouro Preto.

\begin{tabular}{|c|c|}
\hline Doenças & Total de mortes \\
\hline Algumas doenças infecciosas e parasitárias & 3,3 \\
\hline Neoplasias (tumores) & 15,2 \\
\hline Doenças do aparelho circulatório & 35,6 \\
\hline Doenças do aparelho respiratório & 11,9 \\
\hline Algumas infecções Originadas no período perinatal & 3,3 \\
\hline Causas externas de morbidade e mortalidade & 8.8 \\
\hline Demais causas definidas & 21,9 \\
\hline
\end{tabular}

Fonte: DATASUS (2008).

Ressalta-se que o alto percentual de mortes decorrentes de tumores, doenças do aparelho circulatório, respiratórias, infecciosas e parasitárias podem ser decorrentes de hábitos pouco saudáveis, como má alimentação e sedentarismo. As doenças do aparelho circulatório, do aparelho respiratório, neoplasias e parasitárias eventualmente são vinculadas a condições ambientais impróprias ou adversas carecendo maiores estudos a fim de averiguar a proveniência de tais doenças com objetivo de desenvolvimento de medidas de prevenção a fim de reduzir ou mitigar os motivos que possam estar ocasionando tais óbitos.

O Índice para a avaliação do desempenho da política pública de meio ambiente é calculado pelo somatório dos índices Ar, Água, Solo, Biodiversidade, Institucional e Socioeconômica, dado pela seguinte expressão: IDPA = IAR + IÁGUA + ISOLO + IBIOD + IINST + ISOCE, FEAM (2009). Nesse contexto, tendo em vista a inviabilidade da obtenção de dados quantitativos para o cálculo de alguns dos indicadores propostos, o resultado foi exposto em quadro qualitativo. Logo, tem-se que Ouro Preto obteve o seguinte resultado qualitativo na avaliação dos indicadores:

Figura 3 - Indicadores de sustentabilidade de Ouro Preto.

\begin{tabular}{|l|l|l|l|}
\hline Indicador & Ruim & Média & Alta \\
\hline Institucional & \multicolumn{3}{|c|}{ Não se aplica (sem dados). } \\
\hline Ar & \multicolumn{2}{|c|}{ x } \\
\hline Água & & X & \\
\hline Biodiversidade & X & \\
\hline Solo & & & \\
\hline Socioeconomia & X & \\
\hline
\end{tabular}

Fonte: Machado (2014). 
Segundo Ramos (1997), os indicadores e os índices são projetados para simplificar a informação sobre fenômenos complexos de modo a melhorar a comunicação. Podem ser aplicados em uma série de situações problemas como: atribuição de recursos; classificação de locais; cumprimento de normas legais; análise de tendências; informação ao público; investigação científica. Os índices são, portanto a compilação de uma série de dados quantitativos, mensurados e convertidos em dados qualitativos que compõe os indicadores. Logo, pode-se constatar que os dados apresentados de forma qualitativa, ainda que pouco precisos, facilitam o entendimento de dados complexos e auxiliam na avaliação do desempenho da política pública de meio ambiente.

\section{OS INDICADORES DE SUSTENTABILIDADE E O PLANEJAMENTO DA ATIVIDADE TURÍSTICA EM UCS.}

Como apontado anteriormente, dentre as 11 UC de Ouro Preto ${ }^{3}, 5$ são cadastradas em âmbito municipal (Câmara Municipal), 6 em âmbito estadual (Instituto Estadual de Florestas- IEF) e 8 delas constam ainda no cadastro nacional (Cadastro Nacional de Unidades de Conservação - CNUC). Tal panorama deve-se à falta de padronização dos requisitos para a criação da unidade, e o seu cadastramento, nas diferentes esferas governamentais.

A ausência de aporte técnico, a falta de gestão, coordenação e controle pode ocasionar na depredação do atrativo ou no comprometimento das suas características ambientais. Os Indicadores de Sustentabilidade se apresentariam como ferramentas de diagnóstico eficiente para avaliação de integridade física das UCs bem como aporte para o planejamento da atividade de visitação nestas. Na figura que segue, são apresentadas as unidades de conservação existentes em Ouro Preto e a sua condição de conservação frente os indicadores estaduais.

\footnotetext{
${ }^{3}$ No presente trabalho, não foram consideradas as unidades de conservação da categoria Reserva Particular do Patrimônio Natural
} 
Figura 4 - Analise das Unidades de Conservação de Ouro Preto mediante indicadores de sustentabilidade.

\begin{tabular}{|c|c|c|c|}
\hline \multicolumn{4}{|c|}{ ANALISE DAS UNIDADES DE CONSERVAÇÃO DE OURO PRETO - MG } \\
\hline $\begin{array}{c}\text { Indicador } \\
\text { sustentabilidade }\end{array}$ & Presença & Ausência & Observação \\
\hline Institucional & $\begin{array}{l}1 ; 2 ; 3 ; 4 ; 5 ; 6 ; \\
7 ; 8 ; 9 ; 10 ; 11\end{array}$ & - & $\begin{array}{l}\text { Existe orçamento e meios institucionais } \\
\text { que visam assegurar a qualidade deste } \\
\text { indicativo, porém, os mesmos ainda são } \\
\text { insuficientes e ineficazes ou mal } \\
\text { distribuídos. }\end{array}$ \\
\hline $\mathrm{Ar}$ & - & $\begin{array}{l}1 ; 2 ; 3 ; 4 ; 5 ; 6 ; \\
7 ; 8 ; 9 ; 10 ; 11\end{array}$ & $\begin{array}{l}\text { Não existem mecanismos que controlam } \\
\text { sistematicamente e com eficiência a } \\
\text { qualidade do ar nas unidades. }\end{array}$ \\
\hline Água & $1 ; 3 ; 4 ; 5$ & $2 ; 6 ; 7 ; 8 ; 9 ; 10 ; 11$ & $\begin{array}{l}\text { Existe abastecimento de água tratada em } \\
\text { algumas das unidades e sistema de } \\
\text { tratamento de esgoto precário tais como: } \\
\text { fossas sépticas e sumidouros. Porém, a } \\
\text { maioria das unidades apresenta ausência } \\
\text { total de tratamento de água e destinação } \\
\text { de efluentes sanitários. }\end{array}$ \\
\hline Biodiversidade & $\begin{array}{l}1 ; 2 ; 3 ; 4 ; 5 ; 6 ; \\
7 ; 8 ; 9 ; 10 ; 11\end{array}$ & - & $\begin{array}{l}\text { Todas as unidades possuem condições } \\
\text { bióticas relevantes e mecanismos } \\
\text { institucionais que visam assegurar e } \\
\text { resguardar a qualidade das mesmas. }\end{array}$ \\
\hline Socioeconomia & - & $\begin{array}{l}1 ; 2 ; 3 ; 4 ; 5 ; 6 ; \\
7 ; 8 ; 9 ; 10 ; 11\end{array}$ & $\begin{array}{l}\text { As unidades não possuem instrumentos } \\
\text { para obtenção de dados e controle deste } \\
\text { índice. Sendo utilizados dados do } \\
\text { município como um todo. }\end{array}$ \\
\hline Solo & $1 ; 2 ; 3 ; 4 ; 5 ; 10$ & $6 ; 7 ; 8 ; 9 ; 11$ & $\begin{array}{l}\text { As unidades possuem controle parcial } \\
\text { deste índice, em especial no que tange o } \\
\text { controle da utilização de pesticidas, porém, } \\
\text { a destinação adequada de resíduos sólidos } \\
\text { se dá apenas em seis das onze unidades. }\end{array}$ \\
\hline \multicolumn{4}{|c|}{$\begin{array}{l}\text { UNIDADES DE CONSERVAÇÃO ANALISADAS: } \\
\text { Municipais } \\
\text { Parque Natural Municipal das Andorinhas; } \\
\text { Parque Natural Municipal Horto dos Contos; } \\
\text { Parque Natural Municipal de Cachoeira do Campo; } \\
\text { Parque Natural Arqueológico Municipal do Morro da Queimada; } \\
\text { Monumento Natural Municipal Gruta Nossa Senhora da Lapa. } \\
\text { Estaduais } \\
\text { Área de Proteção Ambiental Cachoeira das Andorinhas; } \\
\text { Estação Ecológica do Tripuí; } \\
\text { Floresta Estadual do Uaimii; } \\
\text { Monumento Estadual Municipal do Itatiaia; } \\
\text { Parque Estadual do Itacolomi; } \\
\text { Parque Estadual Serra do Ouro Branco. }\end{array}$} \\
\hline
\end{tabular}

Fonte: Machado (2014).

O Indicador Institucional do município apontou para a existência de recursos financeiros, no entanto, a realidade observada nas UCs, de acordo com figura 5 indica deficiências na aplicação destes recursos para fins preservacionistas e para o ordenamento da atividade turística que, da forma como vem sendo ofertada, pode 
ocasionar em impactos negativos nos atrativos localizados nas Unidades de conservação.

Considerando que das Unidades de Conservação analisadas, apenas uma possui visitação restrita, foi possível constatar que, apesar de abertas para o fluxo turístico, as demais não apresentam estrutura física suficiente para a realização do receptivo. Destacando-se apenas o Parque do Itacolomi, que encontra-se melhor estruturado para a o receptivo. O Parque Natural Municipal Horto dos Contos, o Parque Natural Municipal das Andorinhas e o Monumento Natural Municipal da Gruta Nossa Senhora da Lapa possuem ainda infraestrutura mínima, porém ainda insuficientes para assegurar a integridade dos atrativos. Há ainda carência de hospedagem, acesso, ausência de sinalização adequada para orientação, segurança e interpretação ambiental, atendimento médico, acompanhamento nos passeios turísticos, serviços de alimentação e comercialização de artesanato e divulgação da cultura local.

Indicador ar: Nas unidades de conservação em analise, não há monitoramento institucional regular da qualidade do ar. Logo, não é possível a obtenção de dados consistentes que possibilitem o cálculo do índice que engloba este indicador. Porém, a ocorrência de incêndios são comuns nas Unidades de Conservação em questão.

De acordo com representantes da ONG Brigada 1 - Núcleo Ouro Preto, a maioria dos incêndios ocorridos nas UCs é de origem antrópica e de difícil controle, uma vez que são provocados sem práticas adequadas que assegurariam a conservação do local e à precariedade dos equipamentos de combate, ausência de logística operacional, e de apoio financeiro às equipes de combate a incêndios pelo município. A exposição frequente ao fogo facilita a extinção de espécies nativas, o esgotamento dos solos e cria um ambiente propício para a proliferação de espécies exóticas.

Indicador Água: o uso da água nos atrativos, tem um ciclo característico que viabiliza o impacto ambiental negativo nas UCs. A água é coletada de uma fonte local (rio, lago ou lençol freático), é tratada, utilizada e retorna para um corpo coletor, quando há um. Nesse retorno só excepcionalmente ela conserva as mesmas características de quando foi captada. Ocorrem alterações nas composições de sais, matéria orgânica, temperatura e outros resíduos poluidores.

Os indicadores do sistema de esgotamento sanitário do município de Ouro Preto não são satisfatórios, visto que hoje o sistema tem somente rede coletora de efluentes domésticos em uma parte da cidade (região central e do bairro Itacolomi). No restante do município (principalmente os morros e área periférica) e nas UCs, os efluentes são lançados em galerias de águas pluviais, diretamente nos corpos hídricos, na drenagem natural ou são utilizados sistemas de tratamento individual em desconformidade com os padrões mínimos de construção como é o caso das fossas negras.

Cabe ainda frisar que existe abastecimento de água tratada e sistema de tratamento de esgoto, embora precário, tais como fossas sépticas e sumidouros em 
6 das 11 unidades de conservação analisadas. Em 5 das unidades de conservação analisadas há ausência total de tratamento de água e destinação de efluentes sanitários não atendendo portanto a demanda atual muito menos um eventual aumento nesta proveniente da visitação turística. Condição alarmante esta, tanto para a população residente quanto para os visitantes, dadas às inúmeras doenças com proliferação hídrica existentes

Quanto ao Indicador solo, nas Unidades de Conservação foram relatados problemas com a coleta de lixo, que deveria ser realizada regularmente por órgão público, porém nem sempre ocorre. Há ainda ausência de coleta seletiva regular, embora exista o programa de coleta no município e incentivo a programas de Educação Ambiental, no entanto, os mesmos mostraram-se ainda ineficientes no que tange conter praticas poluentes tais como a deposição irregular de lixo, resíduos em geral, em locais inapropriados próximos às UCs ou em suas vias de acesso, onde há ocorrência frequente de entulho. No que concerne o impacto da visitação nos solos, as trilhas encontradas foram implementadas sem nenhum planejamento prévio desconsiderando as características físicas do solo e a segurança do visitante. As trilhas existentes em geral favorecendo a caminhada em fila indiana. Apenas no Parque Natural Municipal Horto dos Contos, Parque Natural Municipal das Andorinhas, Monumento Natural Municipal Nossa Senhora da Lapa e Parque Estadual do Itacolomi é possível perceber escadas, plataformas e pontes para transpor obstáculos com segurança, assim como a visualização do ambiente a ser visitado, em diversos ângulos. Outro fator relevante são os riscos geológicos que algumas dessas áreas apresentam.

A conceituação de área degradada é bastante discutida nos meios técnicos e acadêmicos, admitindo-se várias definições de acordo com o enfoque desejado. Assim, poderíamos dizer que, a degradação ocorre quando a vegetação e fauna originais são destruídas, removidas ou expulsas, a camada fértil do solo for perdida, removida ou enterrada e a qualidade de vazão do sistema hídrico for alterada (TEIXEIRA; SILVA JUNIOR, 1994).

Nas UCs, foram encontrados ainda pontos erodíveis, onde é possível notar o desgaste das camadas superficiais do solo. Eventualmente, este tipo de impacto associa-se a canais irregulares de escoamento de água, porém, muitos destes podem ser facilmente relacionados à presença antrópica e à extração irregular de rochas para pesquisa e cascalho. Logo, no município o indicador solo encontra-se nos níveis aceitáveis. Porém, nas UCs analisadas, deixa a desejar. Sendo portanto dados incoerentes se não forem analisados concomitantemente.

O Indicador biodiversidade, como constatado anteriormente, em Ouro Preto encontra-se acima da média estadual. Porém, ao analisarmos in loco as fitofisionomias existentes, foi possível constatar que estas sofrem direta ou indiretamente com os processos de perturbação ou degradação. Dentre os fatores observados estão a abertura de vias secundárias para transeuntes e para o pastoreio que desencadeia na compactação do solo, no corte prematuro e desordenados de plantas nativas e favorecem ainda na disseminação de espécies exóticas. As ações depredatórias podem ocorrer ainda no decorrer da atividade de visitação turística em hábitos ecologicamente contestáveis como arrancar 
fragmentos de rocha; apreender animais, em especial pássaros; arrancar orquídeas bromélias, candeias e demais espécies nativas como "lembrança", para comercialização ou como material lenhoso.

No Indicador socioeconômica, entre as possíveis causas das doenças apontadas como principais fatores da mortalidade infantil estão as condições ambientais e socioeconômicas adversas. Ressalta-se que a preservação do patrimônio natural, o desenvolvimento econômico e as atividades turísticas devem ser promovidas de forma que seja assegurado o bem estar da população residente, dentre estes, condições ambientais agradáveis e saudáveis para a população.

Mediante as considerações apresentadas, é possível constatar acerca da utilização dos indicadores como ferramenta para avaliação e planejamento ambiental dos atrativos turísticos, um dos principais empecilhos encontrados é a grande heterogeneidade existente entre os mesmos em relação a elementos específicos do município, como estrutura econômica, espaço geográfico, biodiversidade, entre outros. Os Indicadores aplicados as UCs podem ser observados na figura a seguir.

Figura 6 - Indicadores de sustentabilidade aplicados às UCs de Ouro Preto.

\begin{tabular}{|c|c|c|c|}
\hline Indicador & Ruim & Média & Alta \\
\hline Institucional & & $\mathrm{x}$ & \\
\hline $\mathrm{Ar}$ & & plica (se & \\
\hline Água & & $\mathrm{x}$ & \\
\hline Biodiversidade & & $x$ & \\
\hline Solo & & $x$ & \\
\hline Socioeconomia & $x$ & & \\
\hline
\end{tabular}

Fonte: Machado (2014).

O conceito de qualidade ambiental se altera conforme o local avaliado. E a analise generalista pode não atender às UCs tendo em vista as especificidades locais. No entanto, os indicadores podem, e devem ser utilizados como forma de mensuração da qualidade ambiental municipal, servindo de parâmetro para a análise local, visando subsidiar o planejamento das atividades turísticas contemplando às necessidades locais da população residente sem contrapor-se à ótica do desenvolvimento sustentável.

Tomando-se como premissa os principais impactos a serem considerados na criação de unidades de conservação da natureza, ampliam-se as possibilidades para as atividades sustentáveis de turismo de natureza, ou ecoturismo, Turismo educacional e cultural. A procura por este tipo de atividade cresce notavelmente em todo o mundo, cabendo ao Poder Público, levando em consideração os anseios da comunidade local a ação protagonista no sentido de alavancar a região na conformação de um pólo de turismo de natureza, gerador de empregos, renda e uma melhor qualidade de vida à população do entorno. Tal esforço, agregado à melhorias na infraestrutura e no saneamento público, ocasiona no aumento nos Índices de Desenvolvimento Humano e na qualidade de vida. Para tanto, o envolvimento da comunidade nos planos para conservação de áreas naturais é estratégia fundamental para o sucesso das atividades. 
A Participação popular é um dos elementos centrais na construção das políticas públicas previsto na Constituição Federal de 1988, cuja prerrogativa mudou o modelo de gestão dos municípios. Entretanto, para que a participação seja considerada legitima, na definição das ações prioritárias e adequadas para o desenvolvimento local, é necessário que as informações sejam socializadas, tornadas públicas, no sentido de contribuir para a apropriação do conhecimento sobre o município e o seu funcionamento pela população. Os indicadores são mecanismos eficientes em tal processo de socialização de tais informações. No entanto, só a socialização não atinge o patamar da tomada das decisões mais relevantes. Além disso, os processos participativos requerem aprendizado, tanto por parte do poder público quanto por parte da população.

O SNUC garante a participação popular na gestão das unidades de conservação por intermédio dos conselhos. A referida lei assegura que todas as unidades de conservação contarão com um conselho gestor que deverá ter em sua composição membros representantes das classes populares. Porém, na pratica, tais conselhos deixam a desejar uma vez que as reuniões da maioria dos conselhos não ocorrem de forma regular, há despreparo dos membros e ausência de fiscalização que assegure o bom funcionamento destes. Em algumas das UCs analisadas o conselho gestor sequer foi instituído.

Por fim, Dias (2003) infere que, a falta de planejamento adequado na utilização dos recursos naturais, acarretará em médio prazo, no esgotamento desses recursos, que muitas vezes são irrecuperáveis ou se dá num espaço de tempo muito longo. Logo, frente aos dados analisados é possível observar que a legislação brasileira é complexa, e que prevê diversas ações eficientes para a proteção dos recursos naturais. Porém, a ausências de ações conjuntas e a ausência de dados dificultam a obtenção dos objetivos propostos.

\section{CONSIDERAÇÕES FINAIS}

De acordo com os dados obtidos na pesquisa foi possível averiguar que, embora os índices sejam mecanismos com grande potencial para auxiliar a gestão no que concerne a obtenção de um diagnóstico ambiental do município além de fornecer subsídios para o monitoramento ambiental, planejamento turístico, norteando ações futuras, observou-se que há dificuldades na obtenção dos dados necessários para o cálculo dos mesmos. Não há precisão nas informações. E, embora a ideia da utilização dos índices de qualidade para o monitoramento da qualidade ambiental seja útil, na pratica, por vezes é inviável devido à falta de ações governamentais conjuntas.

Um dos principais empecilhos encontrados na utilização dos indicadores para o planejamento das atividades de visitação turística é a grande heterogeneidade existente entre os mesmos em relação a elementos específicos, como estrutura econômica, espaço geográfico, biodiversidade, entre outros. 
Embora as unidades de conservação seja fator representativo no que tange à qualidade da biodiversidade do município, a falta de monitoramento, de participação popular ativa, além de mecanismos que assegurem o controle e a qualidade do ar, das águas e do solo pode ocasionar em degradação dos seus atrativos naturais.

Frente ao apresentado, constatou-se ainda que a legislação ambiental brasileira é bem estruturada, e os índices de avaliação da Política Ambiental do Meio Ambiente foram formulados visando à eficiência. Porém, as ações governamentais desconexas, a dificuldade na obtenção de dados necessários para o cálculo dos índices que compões os indicadores ambientais, a ausência de efetiva participação ativa da sociedade e o sistema falho de disseminação e socialização das informações torna, por hora, inviável e impraticável o cálculo dos índices e o efetivo monitoramento ambiental.

\section{REFERÊNCIAS}

BARRETTO, Margarita. O imprescindível aporte das ciências sociais para o planejamento e a compreensão do turismo. Horizontes Antropológicos, v. 9, n. 20, p. 15-29. out. 2003,

BARONI, Margareth. Ambigüidades e deficiências do conceito de desenvolvimento sustentável. Revista Administração de Empresas, São Paulo, v. 32, n. 2, p. 14-24, abr./jun. 1992.

BRAGA, Tânia Moreira; Freitas, Ana Paula Gonçalves de. Índice de Sustentabilidade Local: Uma avaliação de sustentabilidade dos municípios do entorno do Parque Estadual do Rio Doce (MG). ENCONTRO DA ASSOCIAÇÃO BRASILEIRA DE ESTUDOS POPULACIONAIS; XIII. Ouro Preto, Minas Gerais, Brasil. 4 a 8 de nov. 2002.

BRASIL. Ministério do Meio Ambiente (MMA). Cadastro Nacional de Meio Ambiente. Disponível em: <http://www.mma.gov.br/areas-protegidas/cadastro-nacional-deucs>. Acesso em: 13 jun. 2014.

\section{. Legislação Ambiental, Águas. Ministério do Meio ambiente.}

Disponível em: <http://www.mma.gov.br/legislacao/agua>. Acesso em: 13 jun. 2014.

. Legislação Ambiental, Áreas Protegidas. Disponível em:

$\overline{<\mathrm{http} / / / w w w . m m a . g o v . b r / l e g i s l a c a o / a r e a s-p r o t e g i d a s>. ~ A c e s s o ~ e m: ~} 13$ jun. 2014.

. Legislação Ambiental, Biomas. Disponível em:

<http://www.mma.gov.br/legislacao/biomas>Acesso em: 13 jun. 2014.

. Legislação Ambiental, Cidades Sustentáveis. Disponível em:

$\overline{<\mathrm{http}: / / w w w . m m a . g o v . b r / l e g i s l a c a o / c i d a d e s-s u s t e n t a v e i s>. ~ A c e s s o ~ e m: ~} 13$ jun. 2014. 
. Legislação Ambiental, Geral. Disponível em:

$\overline{<h t t p: / / w w w . m m a . g o v . b r / l e g i s l a c a o / g e r a l>A c e s s o ~ e m: ~} 13$ jun. 2014.

CORREAA; Luiz Carlos; GALHARTE, Caroline Alves; OLIVEIRA, Maribel Santos Roque de. Os indicadores de qualidade ambiental no órgão estadual de controle ambiental do estado de São Paulo. Artigo Técnico (2010). Disponível em: <http://www.cerpch.unifei.edu.br/arquivos/artigos/2dfed0bf800037ca495fe555ff28169 e .pdf>. Acesso em: 11 jun. 2014.

DAHL, A. L. The big picture: compehensive approaches. In: MOLDAN G.; BILHARZ, S. (Eds.) Sustainability indicators: report of the project on indicators of sustainable development. Chichester: John Wiley \& Sons Ltd., 1997.

DATASUS. Indicadores de Saúde. Disponível em:

<http://www2.datasus.gov.br/DATASUS/index.php?area=0201> Acesso em: 11 jan. 2014.

DIAS, Reinaldo. Gestão ambiental: responsabilidade social e sustentabilidade. São Paulo: Atlas, 2009.

FEAM. Qualidade do ar. Fundação Estadual de Meio Ambiente. Disponível em: <http://www.feam.br/qualidade-do-ar> Acesso em: 20 jun. 2014.

. Índice de Desempenho da Política Ambiental para o estado de Minas Gerais, jun. 2009. Fundação Estadual de Meio Ambiente. Disponível em: $<$ http://semad.mg.gov.br/imagens/stories/indicadores/2009/indicadoresambientais2009-publicado-junho-2011.pdf>. Acesso em: 13 jun. 2014.

FERREIRA, Aracéli Cristina de Souza. Contabilidade ambiental: uma informação para o desenvolvimento sustentável. 2.ed. São Paulo: Atlas, 2007.

FREIRE, Marina Cecília. Saneamento ambiental. Disponível em: <http://www.institutowilliamfreire.org.br/?id_pagina=4>. Acesso em: 13 jun. 2014.

IBGE. Dados Gerais de Ouro Preto, Minas Gerais. Instituto Brasileiro de Geografia e Estatística. Disponível em: <http://www.cidades.ibge.gov.br/painel/ painel.php?lang=\&codmun=314610\&search=|ouro-preto $>$ Acesso em: 20 jun. 2014.

Censo demográfico 2010. Instituto Brasileiro de Geografia e Estatística. 2010. Disponível em: </http://cidades.ibge.gov.br/painel/painel.php?codmun= 310220>. Acesso em: 04 maio 2014.

LISBOA, Igor. EIA/RIMA. Disponível em: <http://pt.shvoong.com/exactsciences/ 1636219-eia-rima-estudo-relat\%C3\%B3rio-impacto/>. Acesso em: 12 jun. 2014.

MERICO, L. F. K. Introdução à economia ecologia. Blumenau: Ed. da FURB, 1996. 
OURO PRETO. Parques Municipais de Ouro Preto, Leis e Decretos. Câmara Municipal. Disponível em: <http://www.cmop.mg.gov.br/index.php?option= com_wrapper\&view=wrapper\&Itemid=51>. Acesso em: 13 jun. 2014.

ONG BRIGADA 1 - NUCLEO OURO PRETO. Ações preventivas. Disponível em: <http://brigada1.weebly.com/> Acesso em: 10 jun. 2013.

PNUD. Programa das Nações Unidas para o Desenvolvimento no Brasil. Atlas do Desenvolvimento Humano. 2000.

PMSBOP. Plano Municipal de Saneamento Básico de Ouro Preto, Minas Gerais. Ouro Preto, dez. 2013.

RAMOS, Tomás B. Sistemas de Indicadores e Índices Ambientais. Comunicação apresentada no $4^{\circ}$ Congresso Nacional dos Engenheiros do Ambiente. Organização: APEA, p. IV33-IV43, Faro, Portugal, 1997.

RUFINO, R. C. Avaliação da qualidade ambiental do município de Tubarão (SC) através do uso de indicadores ambientais. $123 \mathrm{f}$. Dissertação (Mestrado em Engenharia de Produção) - Programa de Pós-Graduação em Engenharia de Produção, Florianópolis, 2002.

SEMAD-MG. Avaliação ambiental estratégica. Disponível em:

<http://www.meioambiente.mg.gov.br/noticias/1/2207-semad-cria-grupo-de-trabalhopara-avaliacao-de-novas-estrategias-para-o-licenciamento->. Acesso em: 10 jun. 2014.

SILVA, C. L. Desenvolvimento sustentável: um conceito multidisciplinar. In: SILVA, CL; MENDES, J. T. G (Org.). Reflexões sobre o desenvolvimento sustentável: agentes e interações sob a ótica multidisciplinar. 1.ed. Rio de Janeiro, 2005, v. 1, p. 11-40.

SIRVINSKAS, L. P. Legislação de direito ambiental. São Paulo: Saraiva, 2002.

SWARBROOKE, J. Turismo sustentabilidade, gestão e marketing. 2.ed. São Paulo: ALEPH. 2000. v. 4.

TEIXEIRA, W. G.; SILVA JR, J. P. S. Recuperação de Áreas Urbanas Degradadas. In: CONGRESSO BRASILEIRO DE ARBORIZAÇÃO URBANA, 2. Anais... São Luís - Ma, 1994, p. 155-162.

Artigo recebido em: 09/10/2014

Artigo aprovado em: 17/03/2016 